NBER WORKING PAPER SERIES

GLOBAL BENEFITS OF MARINE PROTECTED AREAS

James Rising

Geoffrey Heal

Working Paper 19982

http://www.nber.org/papers/w19982

\author{
NATIONAL BUREAU OF ECONOMIC RESEARCH \\ 1050 Massachusetts Avenue \\ Cambridge, MA 02138 \\ March 2014
}

The authors acknowledge support from the School of International and Public Affairs and the Graduate School of Business at Columbia University. This work was supported by the National Science Foundation under Grant No. 1144155. The views expressed herein are those of the authors and do not necessarily reflect the views of the National Bureau of Economic Research.

NBER working papers are circulated for discussion and comment purposes. They have not been peerreviewed or been subject to the review by the NBER Board of Directors that accompanies official NBER publications.

(C) 2014 by James Rising and Geoffrey Heal. All rights reserved. Short sections of text, not to exceed two paragraphs, may be quoted without explicit permission provided that full credit, including $₫$ notice, is given to the source. 
Global Benefits of Marine Protected Areas

James Rising and Geoffrey Heal

NBER Working Paper No. 19982

March 2014

JEL No. Q22

\begin{abstract}
$\underline{\text { ABSTRACT }}$
Case studies suggest that Marine Protected Areas (MPAs) can be effective tools for fishery management. This study uses global datasets of MPAs and stock assessments to estimate the strength and robustness of their benefits. We apply multiple models, including a treatment-control pairing, a logistic model estimated with fixed-effects, and a regression tree to identify key characteristics. We find that regions with significant MPA designations increased their yearly yield by $17 \mathrm{e} 3 \mathrm{MT} / \mathrm{yr}$ while those without experienced a loss of $20 \mathrm{e} 3 \mathrm{MT} / \mathrm{yr}$. On average, a $1 \%$ increase in protected area results in an increase in the growth rate of fish populations by about $1 \%$. Considering only IUCN classified protected areas, and only marine portions of MPAs, growth rates increase $2 \%$ per percent area protected. MPA size is a key parameter which determines their per-area effectiveness. Using these results, we produce an estimate of the economic benefits of protected areas, relative to their costs. About $60 \%$ of country regions currently have insufficient protected areas to generate economic benefits, where the average break-even point for economic benefits of MPAs is at $8.5 \%$ of marine area.
\end{abstract}

\author{
James Rising \\ School of International Affairs \\ Columbia University \\ New York NY 10027 \\ jarising@gmail.com \\ Geoffrey Heal \\ Graduate School of Business \\ 616 Uris Hall \\ Columbia University \\ New York, NY 10027-6902 \\ and NBER \\ gmh1@columbia.edu
}

An online appendix is available at:

http://www.nber.org/data-appendix/w19982 


\title{
GLOBAL BENEFITS OF MARINE PROTECTED AREAS
}

\author{
JAMES RISING, GEOFFREY HEAL
}

\begin{abstract}
Case studies suggest that Marine Protected Areas (MPAs) can be effective tools for fishery management. This study uses global datasets of MPAs and stock assessments to estimate the strength and robustness of their benefits. We apply multiple models, including a treatment-control pairing, a logistic model estimated with fixed-effects, and a regression tree to identify key characteristics. We find that regions with significant MPA designations increased their yearly yield by $17 \mathrm{e} 3 \mathrm{MT} / \mathrm{yr}$ while those without experienced a loss of $20 \mathrm{e} 3$ $\mathrm{MT} / \mathrm{yr}$. On average, a $1 \%$ increase in protected area results in an increase in the growth rate of fish populations by about 1\%. Considering only IUCN classified protected areas, and only marine portions of MPAs, growth rates increase $2 \%$ per percent area protected. MPA size is a key parameter which determines their per-area effectiveness. Using these results, we produce an estimate of the economic benefits of protected areas, relative to their costs. About $60 \%$ of country regions currently have insufficient protected areas to generate economic benefits, where the average break-even point for economic benefits of MPAs is at $8.5 \%$ of marine area.
\end{abstract}

Marine Protected Areas (MPAs) can be very powerful tools for conservation. Within many MPA boundaries, fish biomass, density, average size, and species richness increase drastically (Lester et al., 2009). MPAs also have the potential to benefit adjacent fisheries. These effects have been studied as "benefits over boundaries", in which increased fish biomass diffuses into exploited areas (Gell and Roberts, 2003), and as "savings accounts", able to buffer fluctuations and support resilience (Grafton et al., 2010).

Theoretical models (Polacheck, 1990, Holland and Brazee, 1996, Tuck and Possingham, 2000) and computational models (Walters et al., 1999) have explored the potential for MPAs to benefit exploited fisheries, but previous empirical studies have focused only on specific regions and species (e.g., Sluka et al., 1997, Murawski et al., 2000, Roberts et al., 2001, McClanahan, 
2010). This study is the first global analysis of the benefits of MPAs for harvested fish stocks. We exploit temporal and spatial variation in protected areas as predictors of stock surplus, as new areas are designated as MPAs within the management boundaries of exploited stocks. The designation of new MPAs amounts to a natural experiment whose consequences we study.

The first section describes our dataset, which combines global databases of MPAs, stock assessments, catch time-series, and sea surface temperatures. In the second section, we perform a set of treatment-and-control analyses, by comparing stock assessments in regions that had a concentrated growth of protected areas to those which did not. The third section constructs an extensive model with stock-specific parameters, based on the logistic growth equation. We treat MPAs as mechanisms for enhancing the growth rate parameter of a stock, and explore a number of model formulations. The fourth section displays a regression tree of the stock-specific MPA effects, as a way of identifying which stock and region characteristics drive positive results. The fifth section considers the expected economic benefits of MPAs, and identifies which countries are currently benefiting from their protected area coverage and which could benefit under more coverage.

\section{DATA}

The MPA Global database (Wood, 2007) includes 4383 MPAs, along with their designation date, location, IUCN category, and area (often specifying the marine portion and no-take portion). ${ }^{1}$ Figures 1 and 2 summarize this data.

We use stock assessments from the RAM Legacy Stock Assessment Database (Ricard et al., 2011). The RAM database contains 336 assessments, with an average of 5 time-series of 46 years per assessment. The assessments vary considerably in the variables they include, but of these, 285 assessments contain yearly values which can be interpreted in terms of metric tons (MT) for both the stock and species catch, for an average of 36 years.

\footnotetext{
${ }^{1} \mathrm{MPA}$ regions can include segments of land, such as islands and shoreline. The marine area of an MPA is excludes this area.
} 


\begin{tabular}{rccc} 
& All & Marine & No Take \\
\hline Available: & 4259 & 2489 & 1493 \\
Non-zero: & 4255 & 2489 & 381 \\
Mean $\left(\mathrm{km}^{2}\right):$ & 1166 & 1171 & 203 \\
Total $\left(\mathrm{km}^{2}\right):$ & $5.0 \mathrm{e} 6$ & $2.9 \mathrm{e} 6$ & $3.0 \mathrm{e} 5$ \\
\% of Ocean: & $1.4 \%$ & $0.81 \%$ & $0.08 \%$
\end{tabular}

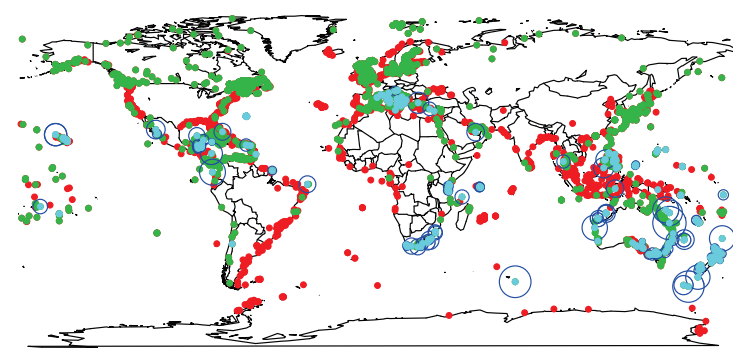

Figure 1. Left: Summary statistics for the MPA Global database. The "Marine" column corresponds to the green and blue dots in the map; the "No Take" column corresponds to only the blue dots. The "\% of Ocean" row shows the portion of the full ocean area included in the MPAs. However, the denominator for calculating this value in the "All" column is inaccurate, since the total protected area sometimes includes non-marine area. Right: Map of MPAs in the MPA Global database. Red dots denote MPAs with only total protected area information available; green dots denote MPAs with non-zero "marine" areas; and blue dots denote MPAs with non-zero "no take" areas. Blue circles around blue dots show the relative sizes of the no take MPAs (but are not to-scale with the geography).

We approximated bounding regions for these assessments, using FAO and country management region shapefiles (see 1). Of the assessment regions in the RAM database, 274 had additional MPAs designated within them during the years when stocks were assessed. Figure 3 shows the spatial distribution of these assessments.

In addition, catches, landed values, and shelf areas by country and distinct sub-country regions were collected from the Sea Around Us Project (Sea Around Us, 2007).

Temperature provides a further key parameter. Changes in sea surface temperatures can have effects throughout the food web, although the effects can vary by species and region. Along the west coast of South America, warm temperatures can signal a shutting-off of nutrient-rich cold water upwelling due to El Nino conditions. In some other stocks, warmer temperatures increase growth rates (Hartnoll, 2001). Long-term temperature changes are also shifting stock ranges producing more complicated impacts (Cheung et al., 2013).

We calculate the average SST anomaly for each region and year, using the Extended Reconstructed SST dataset from NOAA (Smith et al., 2008). 


\section{Number of MPAs designated}

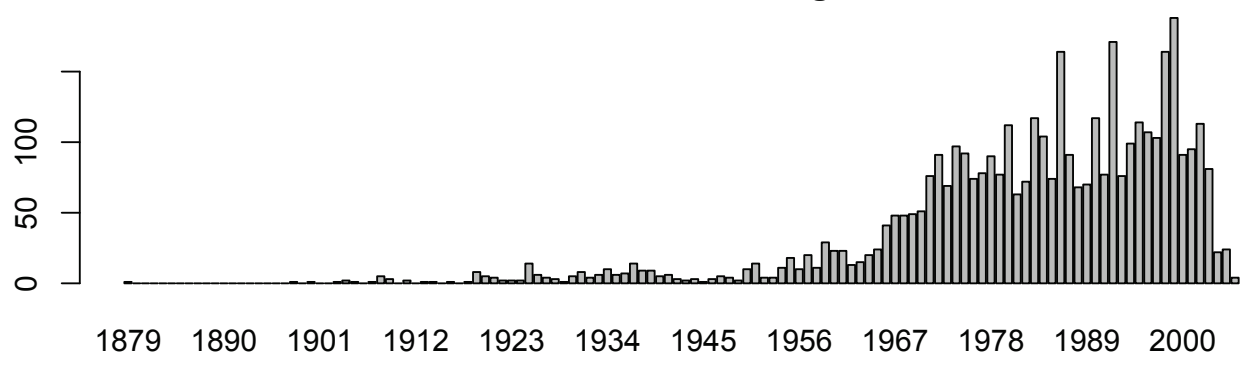

Total Area of MPAs designated

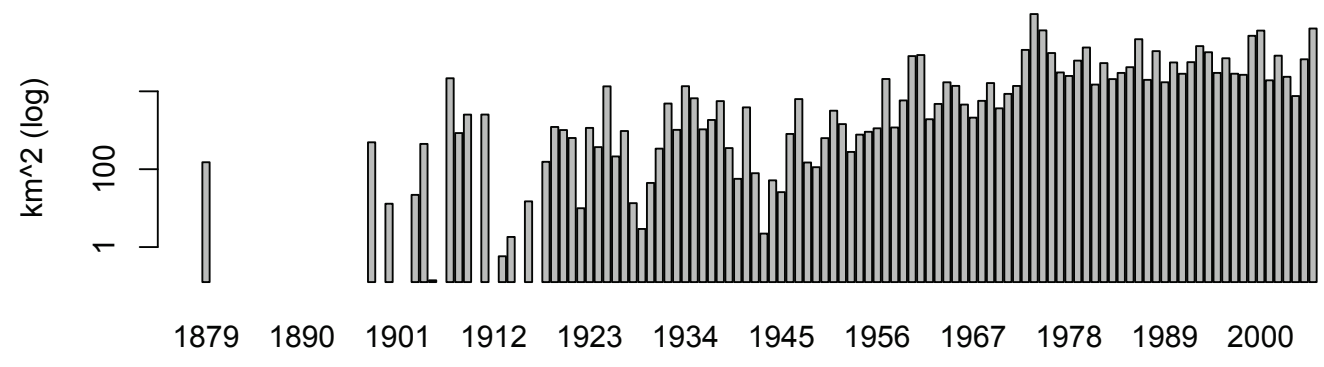

Number of MPAs by Country, in 2006

Total Area of MPAs by Country, in 2006
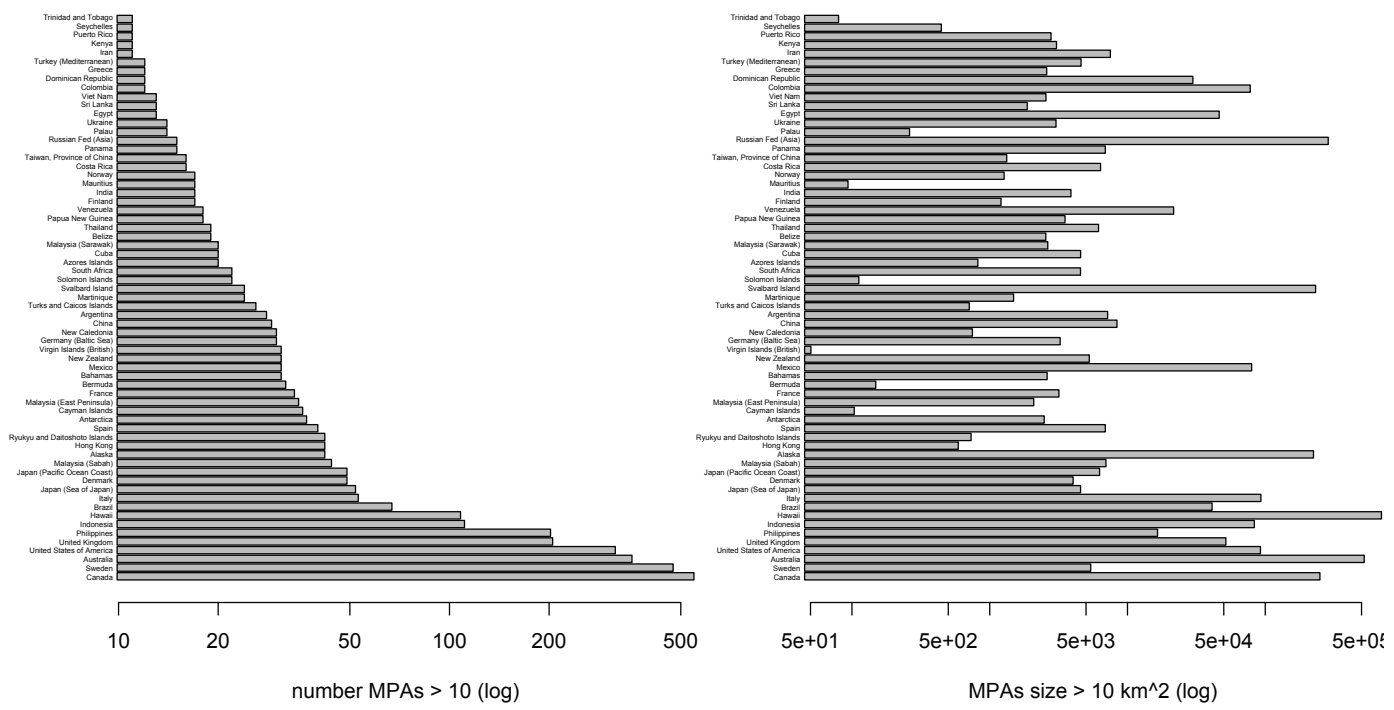

Figure 2. Top: Total MPAs and total MPA area (on a log scale) designated by year. More than 50 new MPAs have been designated yearly since 1970, and over $1000 \mathrm{~km}^{2}$ of ocean has been protected yearly since 1956. Bottom: MPAs and total MPA area by region. Regions designations are from the Sea Around Us project, which divides some countries into smaller regions (for example, Japan is divided into two coasts). Countries have taken very different approaches to designating protected areas, and the regions with the greatest number of MPAs do not always have the greatest area protected. For example, while Sweden has the second most MPAs, it is ranked 27th by total area protected. 

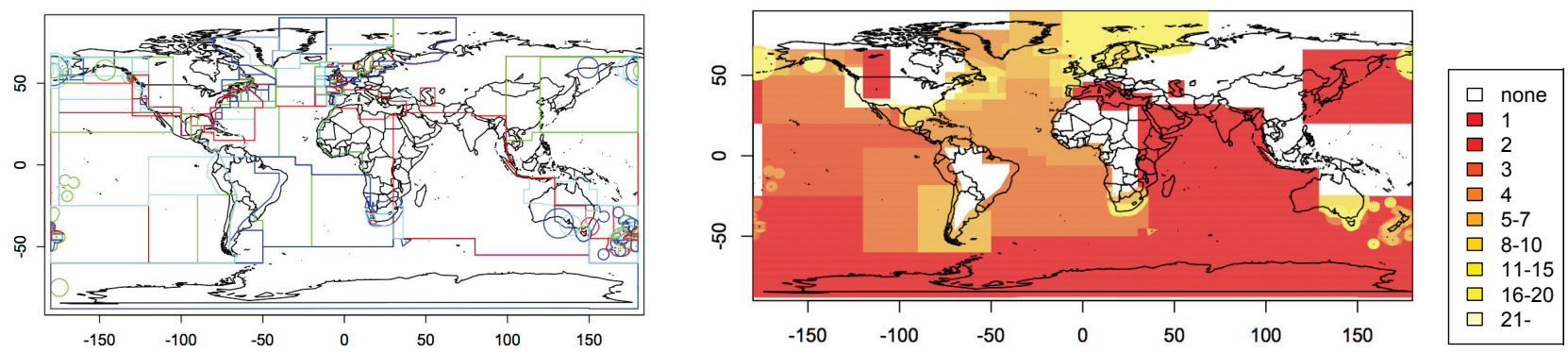

FiguRE 3. Left: Geocoded assessment regions from the RAM database. Right: Heat map of number of assessments used in the analysis.

\section{Treatment and Control Analysis}

We first divide assessments into "treated" and "control" assessments. Treated regions are those which had a period of very little change in their MPA portion, followed by a short period in which large areas were protected, followed by another stable period. Control regions are those for which, over the entire timeseries, the MPA region never increased beyond a threshold. Formally, a regions is categorized as a treated region if

$$
\begin{aligned}
& \frac{M P A\left(t_{1}\right)-M P A\left(t_{0}\right)}{\text { RegionSize }}<x \\
& \frac{M P A\left(t_{2}\right)-M P A\left(t_{1}\right)}{\text { RegionSize }}>y \\
& \frac{M P A\left(t_{3}\right)-M P A\left(t_{2}\right)}{\text { RegionSize }}<x
\end{aligned}
$$

and a control region if

$$
\frac{M P A\left(t_{3}\right)-M P A\left(t_{0}\right)}{\text { RegionSize }}<2 x
$$

We use $x=.15 \%$ and $y=1.5 \%$, which produces 84 treated regions and 93 control regions. Normalized time-series of these two collections show a strong effect (see figure 4), which we analyze more concretely below. 

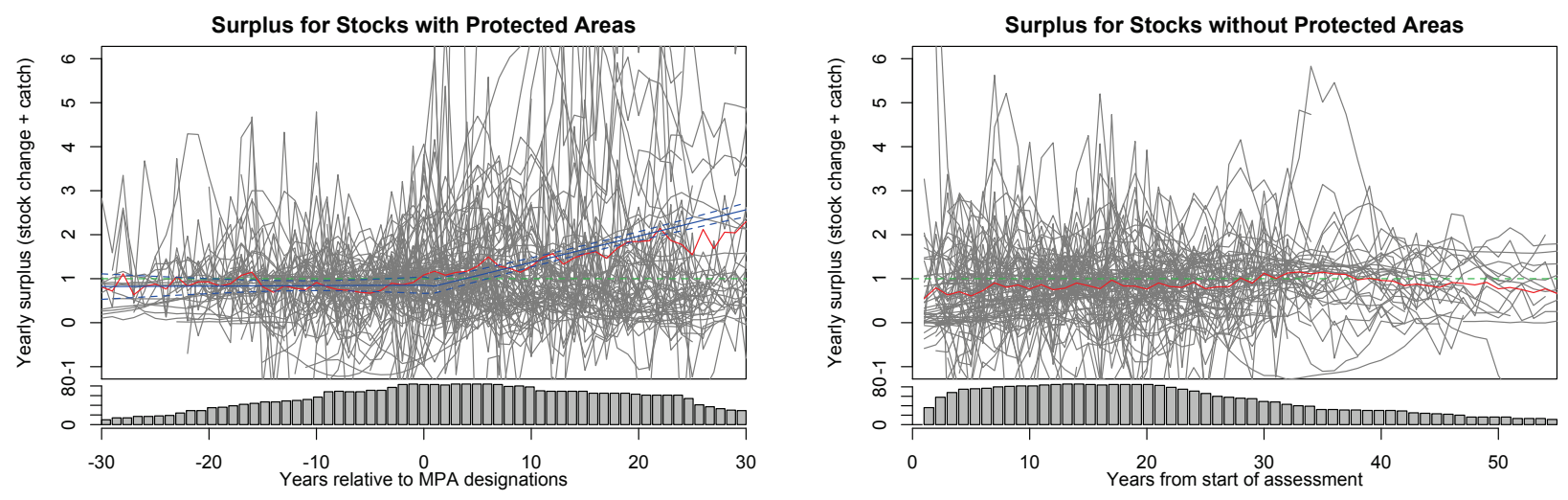

FiguRE 4. Evolution in time of stock surpluses, for "treated" stocks (left) and "control" stocks (right). The histogram below each graph shows the number of assessments available for each year. All stocks are normalized to a pretreatment average of 1 for treated stocks and whole surplus average of 1 for control stocks (green line). The red line shows the average stock surplus in each year. In the left graph, the blue shows estimate and confidence average surplus and post-treatment trend.

\begin{tabular}{lcc}
\hline & No Temp. & With Temp. \\
\hline treated & 0.0999 & 0.0952 \\
& $(0.0862)$ & $(0.0863)$ \\
post & -0.1748 & -0.1893 \\
& $(0.1005)$ & $(0.1007)$ \\
post · treated & $0.2846 *$ & $0.3022^{* *}$ \\
& $(0.1155)$ & $(0.1158)$ \\
\hline $\mathrm{R}^{2}$ & 0.0179 & 0.0189 \\
Adj. R & 0.0062 & 0.0068 \\
Num. obs. & 4912 & 4912 \\
\hline${ }^{* * *} p<0.001,{ }^{* *} p<0.01,{ }^{*} p<0.05$ \\
\end{tabular}

TABLE 1. Two diffrence-in-difference regression models of the effect of MPA designation. The left and right models are identical, except for additional temperature controls in the right model.

A difference-in-difference regression suggests a similar result. The model is as follows:

$$
S_{i t}-S_{i, t-1}+C_{i, t-1}=\alpha \text { treated }+ \text { Btreated } \cdot \text { post }
$$

$S_{i t}-S_{i, t-1}+C_{i, t-1}$ (the change in stock, plus the catch) is the surplus for stock $i$ in year $t$.

We exclude the

The values are normalized as in figure 4 . 


\section{LOGISTIC RESULTS}

The logistic growth model is used to estimate the growth of fish over time, given stock and harvest levels. While logistic growth models are unnaturally simplistic, they are appropriate in situations when age class and ecosystem information is missing. The Gompertz model is also appropriate in these context, and the following analysis is done for it in supplement 4 .

For each stock $i$, we define the surplus or recruitment (which we treat as equivalent) as the change in stock level from one year to the next, plus the catch in that year. Under logistic growth, this is expressed as:

$$
S_{i t}-S_{i, t-1}+C_{i, t-1}=r S_{i, t-1}\left(1-\frac{S_{i, t-1}}{K}\right)=r S_{i, t-1}-\frac{r}{K} S_{i, t-1}^{2}
$$

$S_{i t}-S_{i, t-1}+C_{i, t-1}$ (the change in stock, plus the catch) is the recruitment for stock $i$ in year $t$. Catch includes discards where the data is available.

We hypothesize that the effect of MPAs is a function of the portion of the total assessed region that is protected. We find that the most robust model (reported below) is one in which the protected portion produces additional surplus through changes to the logistic growth rate, $r$, while the ratio $\frac{r}{K}$ remains constant. An increase in $r$ provides an immediate benefit to fishers by providing a greater yearly surplus production. In addition, under these assumptions, if the new growth rate is expressed as a factor increase over the old value, $r_{1}=a r_{0}$, then the new maximum sustainable yield increases by an even greater amount:

$$
M S Y_{1}=\frac{r_{1} K_{1}}{4}=\frac{a r_{0} a K_{0}}{4}=a^{2} M S Y_{0}
$$

By combining the stock assessment time series with the area protection history, the marginal benefit of protecting an additional portion of stock's range can be estimated directly. We use a linear model, estimated by least squares regression with robust standard errors clustered 
at the assessment level:

$$
S_{i t}-S_{i, t-1}+C_{i, t-1}=\left(\alpha_{i}+\beta \frac{M P A_{i t}}{\text { Area }_{i}}+\gamma_{1, i} T_{i, t-1}+\gamma_{2, i} T_{i, t-2}\right) S_{i, t-1}+\kappa_{i} S_{i, t-1}^{2}+\delta_{i}+\epsilon_{i t}
$$

The logistic function is represented here through coefficients estimated on $S_{i, t-1}$ and $S_{i, t-1}^{2}$, and estimated independently for each stock. The marginal change in growth rate, $\beta$, is parameter of interest, and $M P A_{i, t-1}$ is the area protected within the stock assessment region, $A r e a_{i}$. The two previous years' average temperature anomalies are included $\left(T_{i, t-1}\right.$ and $\left.T_{i, t-2}\right)$ as controls on the growth rate. ${ }^{2} \delta_{i}$ is a stock fixed effect. $\epsilon_{i t}$ is a normally distributed error term. In addition, we include time as regressors in some formulations.

The results are shown in table 2, for total protected areas, and for marine-only portions of protected areas, where the data is available.

MPAs often include non-marine regions, such as islands and shoreline, and the marineonly regressions only include the portion of each MPA that is specified as marine. Results for marine-only MPAs tend to be less significant but numerically greater. This is expected, since these regressions represent include only the half of the globally designated MPAs which specify the marine portion of their area (see figure 1). The observations are at the assessmentyear level, so the number of observations does not change between the total and marine-only MPA data, even though less MPA area and fewer MPAs are counted in the marine-only results. These results suggest that marine protection is more beneficial to fish stocks than protection of their adjoining land.

To put these values in perspective, the distribution of growth rates is shown in figure 5. For the histogram, we estimate growth rates after accounting for the global MPA effect, constraining them to be positive. The median growth rate is 0.34 . According to the fourth column (time FE) above model, increasing the protected area range by $10 \%$ would increase this median growth rate by $35 \%$ and the MSY by $83 \%$. The distribution of these percentage

\footnotetext{
${ }^{2}$ This modification allows growth rates to vary systematically, in line with Carson et al. (2009).
} 


\begin{tabular}{|c|c|c|c|c|c|}
\hline & No Temp. & Timeless & Stock Trends & Year FE & Trends-Year \\
\hline \multicolumn{6}{|c|}{ Data: $M P A$ variables represent Total MPA areas } \\
\hline \multirow[t]{2}{*}{$\beta$} & 0.7872 & $1.0824^{*}$ & $1.3263^{* * *}$ & $1.2019^{* *}$ & $1.2968^{* * *}$ \\
\hline & $(0.7530)$ & $(0.6024)$ & $(0.4769)$ & $(0.5589)$ & $(0.4822)$ \\
\hline $\mathrm{R}^{2}$ & 0.5280 & 0.6042 & 0.6375 & 0.6076 & 0.6398 \\
\hline Adj. $R^{2}$ & 0.4844 & 0.5391 & 0.5636 & 0.5402 & 0.5635 \\
\hline \multicolumn{6}{|c|}{ Data: MPA variables represent Marine-only MPA areas } \\
\hline \multirow[t]{2}{*}{$\beta$} & 1.1983 & 2.0525 & 1.3218 & $2.3611^{*}$ & 1.2359 \\
\hline & $(1.9896)$ & $(1.4265)$ & $(1.8871)$ & $(1.3115)$ & $(1.8748)$ \\
\hline $\mathrm{R}^{2}$ & 0.5277 & 0.6040 & 0.6366 & 0.6076 & 0.6390 \\
\hline Adj. $R^{2}$ & 0.4841 & 0.5389 & 0.5625 & 0.5401 & 0.5625 \\
\hline Temperatures & no & yes & yes & yes & yes \\
\hline Stock trends & no & no & yes & no & yes \\
\hline Year FE & no & no & no & yes & yes \\
\hline Num. obs. & 10093 & 10093 & 10093 & 10093 & 10093 \\
\hline
\end{tabular}

${ }^{* * *} p<0.01,{ }^{* *} p<0.05,{ }^{*} p<0.1$

TABLE 2. The estimated marginal change to the growth rate for protecting a portion of an assessment. To capture this entire benefit, $100 \%$ of the region would need to be protected, a value which is outside of the range of our data. The first column has no temperature or time regressor, while all other columns include temperature controls. The second column includes temperatures, but not time. The middle third includes assessment-specific trends. The fourth column has a fixed effect for each year. The fifth column includes both year fixed effects and stock trends.

increase in growth rate per percent increase in protected area is also shown in the lower-right graph of figure 5 .

The spatial distribution of positive and negative estimated benefits from MPAs is displayed in figure 6.

These estimates rely on variation in the MPA area over time. Forms of fishery management that operate through catch restrictions (e.g., ITQs, season restrictions, horsepower limits) are captured by changes in the observed catch. Gear restrictions which can allow catch to be more selective, however, are not accounted for and could explain some of the benefits here attributed to MPAs if these restrictions were implemented simultaneously. A great number of additional factors are missing from this model: environmental forcings, species interaction, 

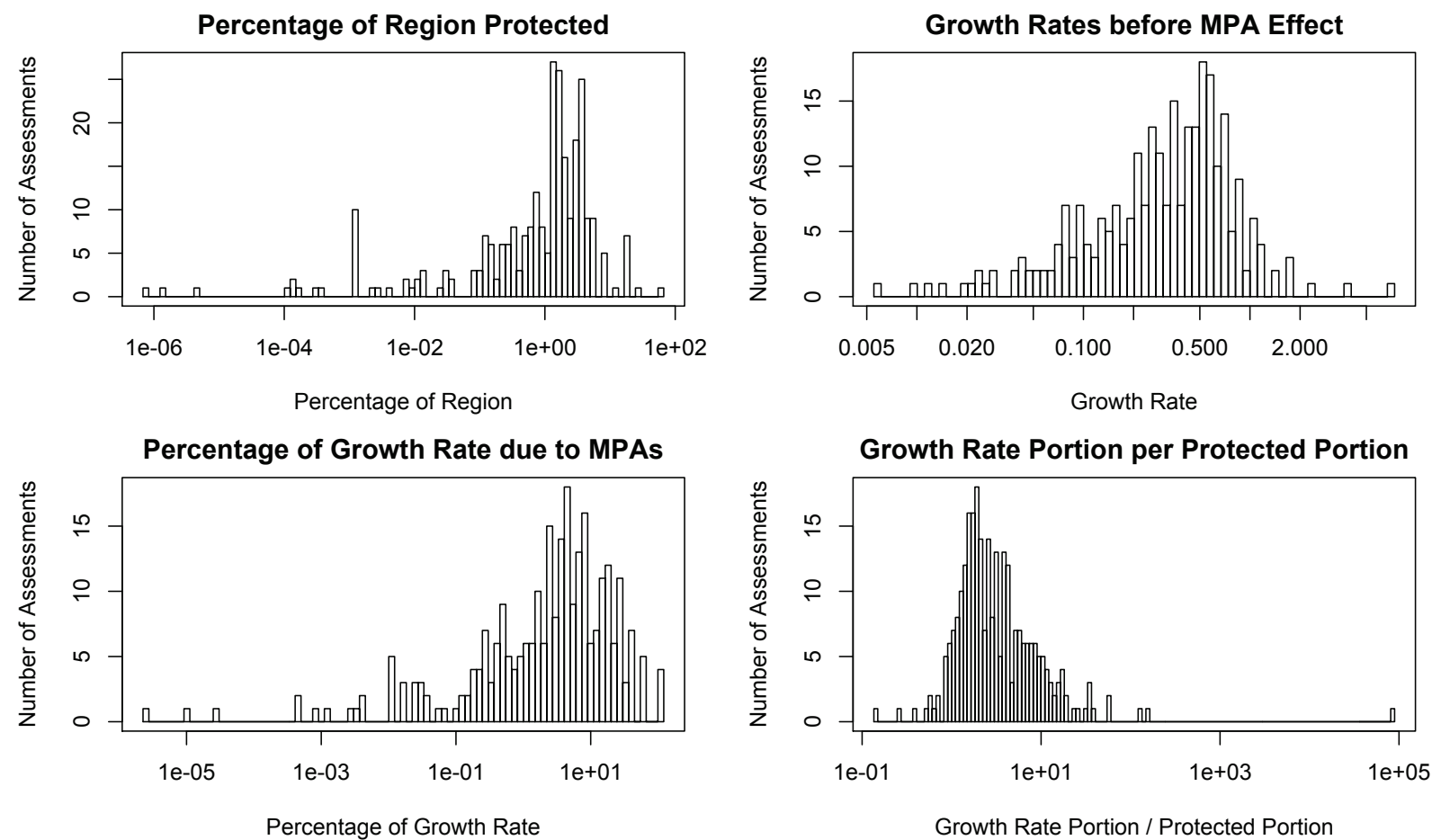

FiguRE 5. Upper-left: A histogram of the protected portion of each assessed area. The middle $50 \%$ have protected portions between .3\% to $2.8 \%$. Upper-right: A histogram of the growth rates, before accounting for protected areas, according to the fourth column (time FE) model and for growth rates estimated as non-negative. Lower-left: Percentage of the observed total growth attributable to protected areas in 2006. Lower-right: Relationship between marginal increases in protected areas and increases in growth rates.

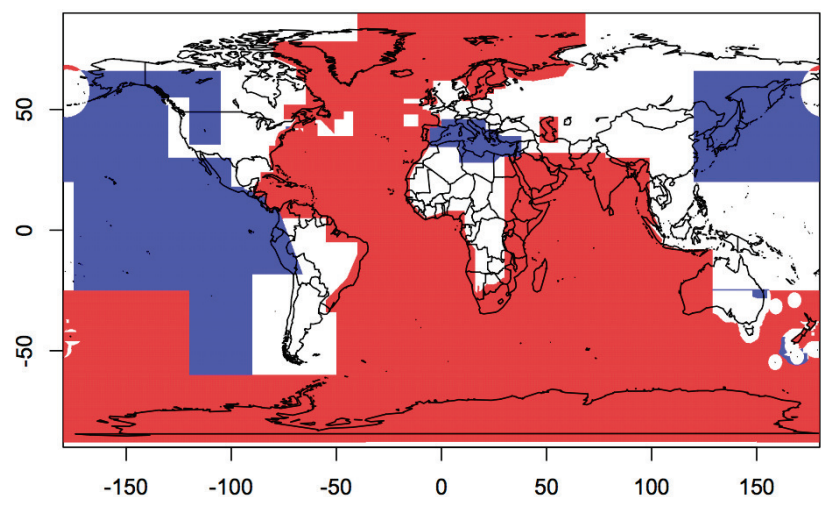

FIGURE 6. Regions with positive and negative estimated effects from MPAs. Blue regions had $>\frac{2}{3}$ of assessed stocks showing positive benefits; red regions had $>\frac{2}{3}$ of assessed stocks showing negative benefits. Although the growth model shows much more consistent benefits from MPAs, it does not account for inherent stock-level growth dynamics like the linear model. 
and other anthropogenic effects. However, these are unlikely to correlate either strongly or positively with MPA designation.

This analysis does not distinguish between the benefits that accrue only to the exploited region, separately from the protected region. However, most assessed regions have a small fraction of their area protected (the median protected portion is $1.4 \%$; see figure 5 ), so that if the assessment regions describe the natural range of a stock, the surplus would quickly become available to all fishers.

IUCN Results. IUCN categorization can be used as a indicator of management regime. Of the 4259 MPAs in our data set, 3545 have IUCN classification, as shown in table 3.

Accounting for the total area designed accross all IUCN classified MPAs, the coefficient $\beta$ is $1.2017 \pm 0.3593^{* * *}$, under the time FE model. Accounting only for the marine area, where available, the coefficient is $1.3207 \pm 1.4715$. The significance decreases considerably due to the half of the MPA observations which are dropped due to missing marine-portion data. A $10 \%$ increase in protected area increases the median growth rate by $35 \%$. The results are comparable to the total sample results.

The estimates of effects by IUCN category vary greatly, but estimates for classifications with more data tend to approach the general model. The results suggest that Habitat/Species Management Area are amongst the most effective IUCN classifications. The significance of this result may simply reflect the larger set of available data, representing almost twice the MPAs of any other IUCN catagory. However, it may also derive from the concerted management practices behind IUCN category IV regions. Protected Landscape/Seascape MPAs, which seek to secure the long-term capacity for human interaction, do worst. The low performance of String Nature Reserves is at odds with regression results that include all no-take reserve areas, which are positive, but both are highly insignificant due to the lack of data. In general, the variance 


$\begin{array}{rrlc}\text { IUCN } & & \text { N } & \beta \text { Estimate (trends) } \\ \text { Ia } & \text { Strict Nature Reserve } & 430 & -1.9900 \pm 2.3739 \\ \text { Ib } & \text { Wilderness Area } & 59 & \text { (insufficient data) } \\ \text { II } & \text { National Park } & 569 & 0.3430 \pm 0.8792 \\ \text { III } & \text { Natural Monument or Feature } & 130 & \text { (insufficient data) } \\ \text { IV } & \text { Habitat/Species Management Area } & 1084 & 2.5883 \pm 0.3576^{* * *} \\ \text { V } & \text { Protected Landscape/Seascape } & 611 & -5.8342 \pm 13.0779 \\ \text { VI } & \text { Sustainable use protected area } & 662 & 3.0647 \pm 3.5272\end{array}$

TABLE 3. MPAs with IUCN classification in the MPA Global database. The $\beta$ Estimate column shows the estimated coefficient $\beta$ in the stock trends model for total MPA area.

\section{REGRESSION TREE}

To determine what factors most influence the effectiveness of MPAs, we estimate the MPA effect for each assessment individually, and build a regression tree with a wide variety of factors, shown in table 4 . These include both region and fish characteristics.

Regression trees identify the natural divisions that associate coefficient estimates and input parameters (Breiman et al., 1984). Each decision branch of the tree is a division in the data or a subset of the data, and is characterized by an average coefficient estimate and a number of observations. Note that the highest-level node, representing the average coefficient across all data when estimated independently, is negative.

\begin{tabular}{|c|c|}
\hline Parameter & Notes \\
\hline Assessed region size & in $\mathrm{km}^{2}$ \\
\hline Protected area size & in $\mathrm{km}^{2}$ \\
\hline Portion of assessed region protected & \\
\hline Latitude and Longitude & \\
\hline Productivity & as the maximum recorded catch, divided by the region size \\
\hline Logistic growth rate $(r)$ & \\
\hline Logistic carrying capacity $(K)$ & \\
\hline The country, or multinational & \\
\hline Age of recruits and recruited biomass & in yr, as used for estimating stocks (by individuals, $\mathrm{N}=210$; by biomass, $\mathrm{N}=182$ ) \\
\hline Maximum sustainable yield & in $\operatorname{MT}(\mathrm{N}=193)$ \\
\hline Age for computing mortality & in $\operatorname{yr}(\mathrm{N}=157)$ \\
\hline Habitat & pelagic marine; demersal marine; diadromous; wholly freshwater $(\mathrm{N}=142)$ \\
\hline Sex of spawners & for estimating stocks $(\mathrm{N}=129)$ \\
\hline Minimum age of spawners & in $\operatorname{yr}(\mathrm{N}=128)$ \\
\hline Natural mortality & per year $(\mathrm{N}=126)$ \\
\hline Age at $50 \%$ maturity & in $\operatorname{yr}(\mathrm{N}=122)$ \\
\hline
\end{tabular}

TABLE 4. The variables used to in the regression tree construction to predict effect sizes, as estimated by the logistic equation. 
Predictors of assessment MPA effect coefficients

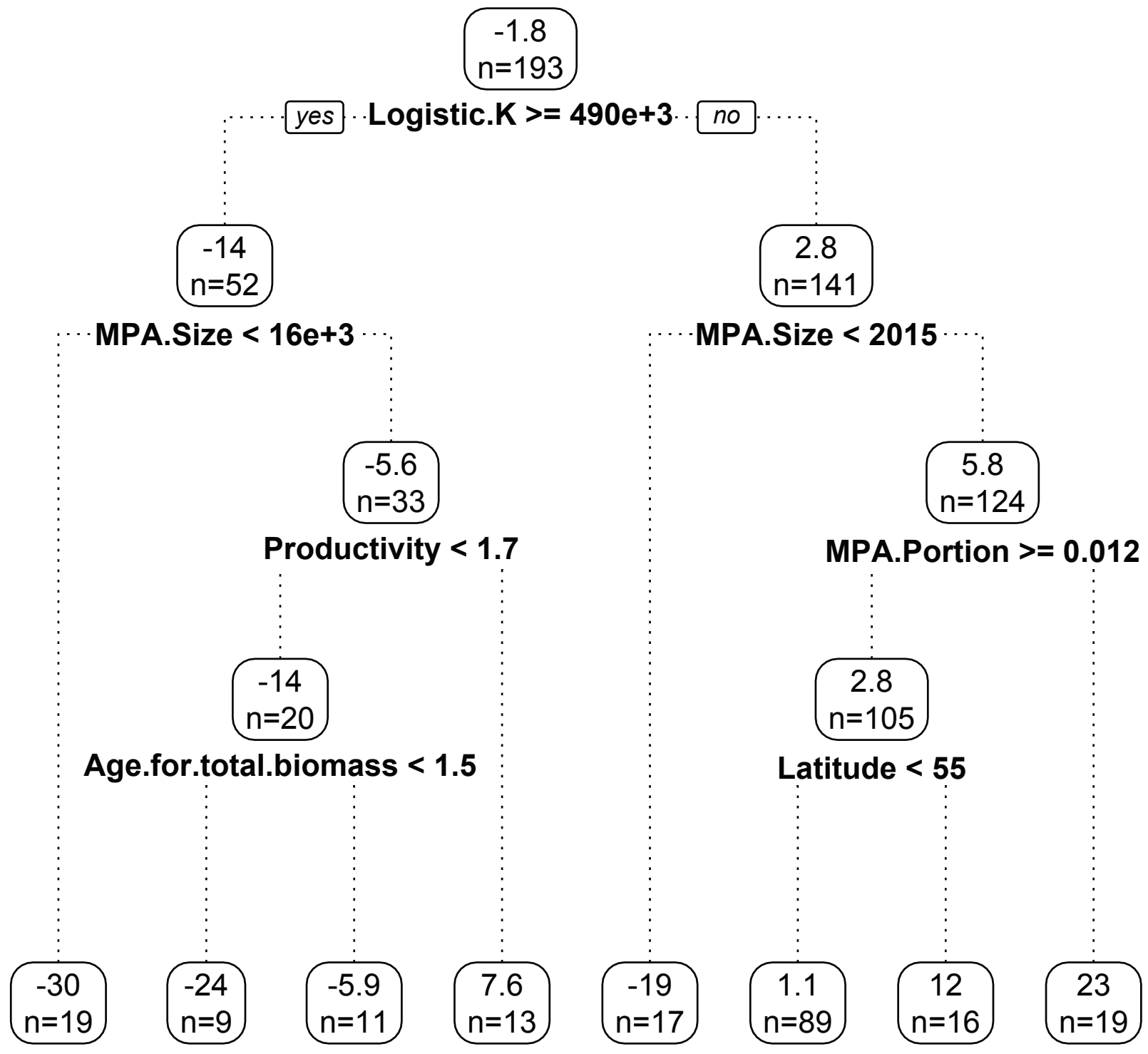

FiguRE 7. A regression tree to explain stock-specific estimates of the benefits of MPAs, according to the logistic model.

The first branch of the regression tree is determined by the potential size of the stock, which also relates to its range. Large stocks (left branch) typically are not benefited by protected areas unless the protected areas are large and the stock is very productive. For smaller stocks, all branches show positive effects from MPAs, with the largest effects from large MPAs within even larger assessment regions. High latitude stocks also show large benefits from MPAs, probably due to successful management in Alaska and northern Europe. 
A few missing parameters are notable. In particular, the country is not a top-level predictor. Age only shows up on the lower left branch (age for estimating biomass), suggesting that both long- and short-lived species benefit. Finally, habitat type is not a top-level predictor.

\section{ECONOMIC ANALYSis}

To translate these effects into economic benefits, we use the Sea Around Us landed catch values. The additional value attributable to protecting a given area of ocean is,

$$
V(M P A)=\beta \frac{M P A}{\text { Area }} \sum_{i} p_{k} \bar{S}_{k}
$$

where $\bar{S}_{k}$ is the steady-state stock for species $k$, and $p_{k}$ is that species the landing price per MT. The steady-state stock is difficult to estimate, so we take the catch as a lower bound on the stock and produce a conservative estimate of the benefits.

Balmford et al. (2004) estimated global marginal costs of maintaining MPAs as

$$
\log _{10} \frac{\text { cost }}{M P A}=5.02-.8 \log _{10}(M P A)
$$

We combine these to produce a profit function, and find its root, which is the point at which estimated economic benefits exceed estimated costs. Of 234 countries or large marine regions, 71 have enough area protected to have a net economic benefit, 141 currently have a net loss, and 22 generate too little rent for any amount of protected area to generate surplus sufficient for an economic gain. The mean portion to protect to generate an economic surplus is $8.5 \%$, while the current protected region, averaged by country as a portion of EEZs, is $2 \%$. A table of these countries and their key parameters is listed in appendix 5 .

\section{COnCLusions}

There are a number of caveats to the results presented here. It is likely that less than a third of MPAs are effectively managed and protected (Kelleher, 1996, Pauly et al., 2002). This 


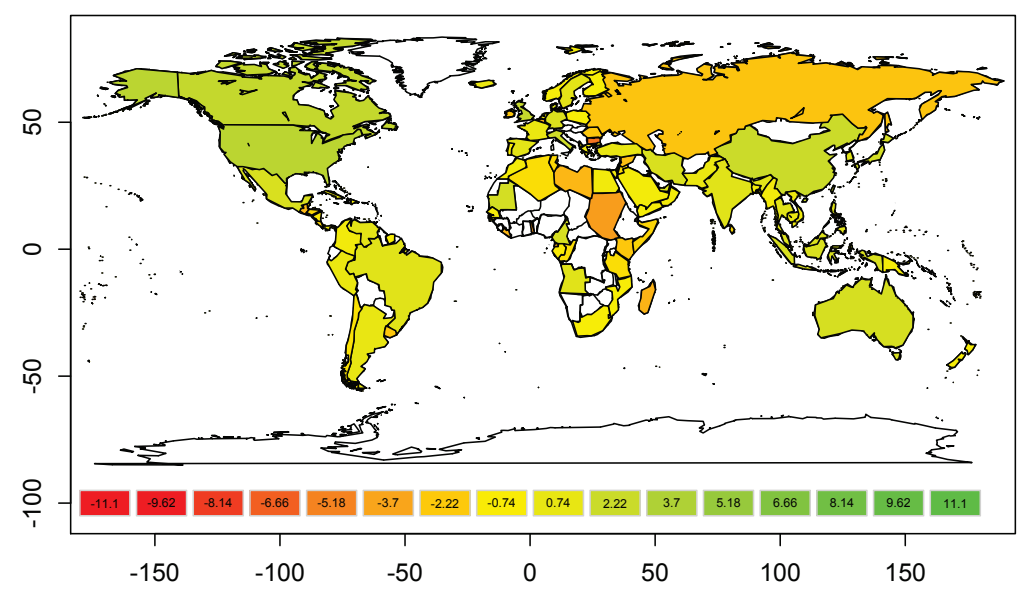

Figure 8. Current status of MPA costs and benefits: green denotes countries for which economic benefits exceed costs; orange and red for those below that threshold.

suggests that our results are conservative and that well-protected MPAs may have greater benefits. However, the RAM database is also biased toward developed countries, due to the dearth of scientific assessments in developing countries. The true global average benefit, and potential average benefit for MPAs may be outside of the confidence intervals of our estimate.

This analysis provides a new entry point for exploring a wide variety of topics, including the institutional features that support effective MPAs (Charles and Wilson, 2009) and the role of fish mobility (Hilborn et al., 2004) and growth rates (Roberts et al., 2001) on MPA effectiveness.

The utility of closed areas for fishers results from the mobility and dispersal of fish: while fish stocks can benefit from MPAs directly by gaining higher levels of biomass and yearly recruitment, fishers only benefit when a portion of this greater stock reaches exploited areas.

Our results corroborate evidence from Guidetti and Claudet (2010) that CPUE within MPAs can be twice that of surrounding areas. This suggests that MPAs can be amongst the most effective forms of fishery management, and future work needs to explore the conditions that affect the distribution of benefits. 


\section{REFERENCES}

Balmford, A., Gravestock, P., Hockley, N., McClean, C. J., and Roberts, C. M. (2004). The worldwide costs of marine protected areas. Proceedings of the National Academy of Sciences of the United States of America, 101(26):9694-9697.

Breiman, L., Friedman, J., Stone, C. J., and Olshen, R. A. (1984). Classification and regression trees. CRC press.

Carson, R. T., Granger, C., Jackson, J., and Schlenker, W. (2009). Fisheries management under cyclical population dynamics. Environmental and resource economics, 42(3):379410.

Charles, A. and Wilson, L. (2009). Human dimensions of marine protected areas. ICES Journal of Marine Science: Journal du Conseil, 66(1):6-15.

Cheung, W. W., Watson, R., and Pauly, D. (2013). Signature of ocean warming in global fisheries catch. Nature, 497(7449):365-368.

Gell, F. R. and Roberts, C. M. (2003). Benefits beyond boundaries: the fishery effects of marine reserves. Trends in Ecology \& Evolution, 18(9):448-455.

Grafton, R. Q., Pham, V. H., Kompas, T., et al. (2010). Saving the seas: the economic justification for marine reserves. Made available in DSpace on 2010-12-20T06: 03: $29 Z$ (GMT). No. of bitstreams: 1 Kompas_Saving2004. pdf: 376160 bytes, checksum: er74826bb428351e3c1d15104dd20d98 (MD5) Previous issue date: 2010-10-28T00: 25: $01 Z$.

Guidetti, P. and Claudet, J. (2010). Comanagement practices enhance fisheries in marine protected areas. Conservation Biology, 24(1):312-318.

Hartnoll, R. G. (2001). Growth in crustaceatwenty years on. In Advances in Decapod Crustacean Research, pages 111-122. Springer. 
Hilborn, R., Stokes, K., Maguire, J.-J., Smith, T., Botsford, L. W., Mangel, M., Orensanz, J., Parma, A., Rice, J., Bell, J., et al. (2004). When can marine reserves improve fisheries management? Ocean \& Coastal Management, 47(3):197-205.

Holland, D. S. and Brazee, R. J. (1996). Marine reserves for fisheries management. Marine Resource Economics, 11:157-172.

Kelleher, G. (1996). A global representative system of marine protected areas. Ocean $\&$ coastal management, 32(2):123-126.

Lester, S. E., Halpern, B. S., Grorud-Colvert, K., Lubchenco, J., Ruttenberg, B. I., Gaines, S. D., Airamé, S., and Warner, R. R. (2009). Biological effects within no-take marine reserves: a global synthesis. Marine Ecology Progress Series, 384:33-46.

McClanahan, T. R. (2010). Effects of fisheries closures and gear restrictions on fishing income in a kenyan coral reef. Conservation Biology, 24(6):1519-1528.

Murawski, S., Brown, R., Lai, H., Rago, P., and Hendrickson, L. (2000). Large-scale closed areas as a fishery-management tool in temperate marine systems: the georges bank experience. Bulletin of Marine Science, 66(3):775-798.

Pauly, D., Christensen, V., Guénette, S., Pitcher, T. J., Sumaila, U. R., Walters, C. J., Watson, R., and Zeller, D. (2002). Towards sustainability in world fisheries. Nature, 418(6898):689-695.

Polacheck, T. (1990). Year around closed areas as a management tool. Natural Resource Modeling, 4(3):327-354.

Ricard, D., Minto, C., Jensen, O., and Baum, J. (2011). Examining the knowledge base and status of commercially exploited marine species with the ram legacy stock assessment database. fish and fisheries.

Roberts, C. M., Bohnsack, J. A., Gell, F., Hawkins, J. P., and Goodridge, R. (2001). Effects of marine reserves on adjacent fisheries. science, 294(5548):1920-1923. 
Sea Around Us (2007). A global database on marine fisheries and ecosystems. fisheries centre, university british columbia, vancouver, canada. http://seaaroundus.org/.

Sluka, R., Chiappone, M., Sullivan, K., and Wright, R. (1997). The benefits of a marine fishery reserve for nassau grouper epinephelus striatus in the central bahamas. In Proceedings of the 8th International Coral Reef Symposium, Panama, volume 2, pages 1961-1964.

Smith, T. M., Reynolds, R. W., Peterson, T. C., and Lawrimore, J. (2008). Improvements to noaa's historical merged land-ocean surface temperature analysis (1880-2006). Journal of Climate, 21(10):2283-2296.

Tuck, G. N. and Possingham, H. P. (2000). Marine protected areas for spatially structured exploited stocks. Marine Ecology-Progress Series, 192:89-101.

Walters, C., Pauly, D., and Christensen, V. (1999). Ecospace: prediction of mesoscale spatial patterns in trophic relationships of exploited ecosystems, with emphasis on the impacts of marine protected areas. Ecosystems, 2(6):539-554.

Wood, L. J. (2007). Mpa global: A database of the world's marine protected areas. http: //www.mpaglobal .org. 